BNL-112647-2016-JA

\title{
A novel small molecule compound of Lithium Iodine and 3-Hydroxypropionitride as Solid-state Electrolyte for Lithium-Air Batteries
}

Fang-Chao Liu, Zulipiya Shadike, Xiao-Fang Wang, Si-Qi Shi, Yong-Ning Zhou, Guo-Ying Chen, Xiao-Qing Yang, Lin-Hong Weng, Jing-Tai Zhao, and Zheng-Wen Fu

Submitted to Inorganic Chemistry

July 2016

Chemistry Department

Brookhaven National Laboratory

\section{U.S. Department of Energy USDOE Office of Energy Efficiency and Renewable Energy (EERE)}

Notice: This manuscript has been authored by employees of Brookhaven Science Associates, LLC under Contract No. DE- SC0012704 with the U.S. Department of Energy. The publisher by accepting the manuscript for publication acknowledges that the United States Government retains a non-exclusive, paid-up, irrevocable, world-wide license to publish or reproduce the published form of this manuscript, or allow others to do so, for United States Government purposes. 


\section{DISCLAIMER}

This report was prepared as an account of work sponsored by an agency of the United States Government. Neither the United States Government nor any agency thereof, nor any of their employees, nor any of their contractors, subcontractors, or their employees, makes any warranty, express or implied, or assumes any legal liability or responsibility for the accuracy, completeness, or any third party's use or the results of such use of any information, apparatus, product, or process disclosed, or represents that its use would not infringe privately owned rights. Reference herein to any specific commercial product, process, or service by trade name, trademark, manufacturer, or otherwise, does not necessarily constitute or imply its endorsement, recommendation, or favoring by the United States Government or any agency thereof or its contractors or subcontractors. The views and opinions of authors expressed herein do not necessarily state or reflect those of the United States Government or any agency thereof. 


\title{
A novel small molecule compound of Lithium Iodine and 3-Hydroxypropionitride as Solid-state Electrolyte for Lithium-Air Batteries
}

\author{
Fang-Chao Liu ${ }^{\dagger}$, Zulipiya Shadike ${ }^{\dagger}$, Xiao-Fang Wang $^{\ddagger}$, Si-Qi Shi ${ }^{\ddagger *}$,Yong-Ning Zhou ${ }^{\perp}$, Guo-Ying \\ Chen $^{\dagger}$, Xiao-Qing Yang ${ }^{\S}$, Lin-Hong Weng ${ }^{\dagger}$, Jing-Tai Zhao ${ }^{\ddagger *}$ and Zheng-Wen Fu ${ }^{\dagger *}$
}

\footnotetext{
${ }^{\dagger}$ Shanghai Key Laboratory of Molecular Catalysts and Innovative Materials, Department of Chemistry \& Laser Chemistry Institute, Fudan University, Shanghai 200433, P.R. China

‡ School of Materials Science and Engineering, Shanghai University, Shanghai 200444, P.R. China

$\S$ Chemistry Department, Brookhaven National Laboratory, Upton, New York 11973.

${ }^{\perp}$ Department of Materials Science, Fudan University, Shanghai 200433, P.R. China
}

\begin{abstract}
A novel small molecule compound of LiI 3-hydroxypropionitrile (HPN) has been successfully synthesized. Our combined experimental and theoretical studies indicated that LiIHPN is a Li-ion conductor, which is utterly different from the $\mathrm{I}^{-}$anion conductor of $\mathrm{LiI}(\mathrm{HPN})_{2}$ reported previously. Solid-state lithium-air batteries based on LiIHPN as the electrolyte exhibit a reversible discharge capacity of more than $2100 \mathrm{mAh} \mathrm{g}^{-1}$ with cyclic performance over 10 cycles. Our findings provide a new way for the design new solid-state electrolytes towards high performance lithium-air batteries.
\end{abstract}

Keywords: Solid-state electrolyte; Small molecule; Lithium-air battery 


\section{Introduction}

The extensive attention has been focused on the development of solid electrolytes for all-solid-state high energy lithium-air batteries due to their chemical /electrochemical stabilities and their non-permeability of oxygen, carbon dioxide and moisture in air [1-4]. Considering the critical role of the solid-state electrolyte for $\mathrm{Li}$ ion migration across the all-solid-state cell, and the electrochemical reaction only takes place at a three-phase zone composed of oxygen gas/air electrode/solid electrolyte, the development of a high-quality interface between the solid electrolyte and air electrode is very important for high performance all-solid-state lithium-air batteries. So far, two general classes of solid electrolytes for all-solid-state lithium-air batteries have been developed: inorganic ceramics [5-6] and organic polymers [7-9]. However, the ceramic electrolytes are hard solids, and the polymer electrolytes have chain entanglement and limited polydispersity. Therefore, their contact areas in the interface between solid electrolytes and air electrodes are much smaller than that between liquid electrolyte and air electrode. Here, we reported a new solid-state Li-ion conductor -LiI 3-hydroxypropionitrile (HPN), which is made up of organic and inorganic molecules. In this small molecule electrolyte, lithium ions are coordinated by discrete low molecular weight ligands such as nitrile group (-CN), hydroxyl group (-OH) and I atoms. Such a new solid electrolyte has the feature of high monodispersity and is expected to improve the performance of the solid-state rechargeable lithium-air battery because of good interfacial contact between electrolyte and electrodes. Previous study suggested that the small molecule compound of $\mathrm{LiI}(\mathrm{HPN})_{2}$ is an $\mathrm{I}^{-}$anions conductor [10-13]. In this work, a novel class of $\mathrm{Li}^{+}$cation conductor -LiIHPN is used in all-solid-state lithium-air batteries for the first time.

\section{Experimental and theoretical methods}

\subsection{Synthesis}

Preparation of materials and electrodes: $\operatorname{LiI}(\mathrm{HPN})_{2}$ (Single crystal synthesized by reference [10]) and highly pure LiI crystal (99.999\% metals basis, Alfa Aesar) are prepared 


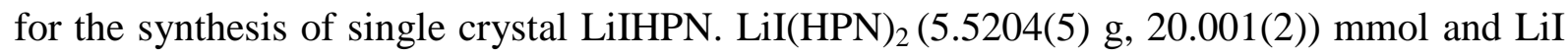
(2.6672(5)g, 20.002(4) mmol) are mixed and stirred at $130^{\circ} \mathrm{C}$ for $48 \mathrm{~h}$ into homogeneous liquid in an argon-filled glove box. Obtained LiIHPN liquid is stored in an oven at the designed temperatures from $90{ }^{\circ} \mathrm{C}$ to $80{ }^{\circ} \mathrm{C}$ with the decreasing step $0.5^{\circ} \mathrm{C} /$ day. After three weeks, single crystal LiIHPN is obtained. The LiIHPN powder can be simply synthesized by annealing the mixture of $\mathrm{LiI}$ and $\operatorname{LiI}(\mathrm{HPN})_{2}$ at $130{ }^{\circ} \mathrm{C}$ for $48 \mathrm{~h}$.

Three-dimensional graphene: Three-dimensional graphene (3D-G) is prepared by a chemical reduction-induced self-assembly method [14] with a hydroiodic acid (HI) as the reducing agents. In brief, $2.2 \mathrm{~mL}$ with a concentration of $46.5 \mathrm{mg} \mathrm{mL}^{-1} \mathrm{HI}$ are added to the graphene oxide suspension ( $2.8 \mathrm{~mL}$ with a concentration of $3.0 \mathrm{mg} \mathrm{mL}^{-1}$ ) to form the mixture. Then, such a mixture is sonicated for $10 \mathrm{~min}$ and transferred to an oil bath at $90{ }^{\circ} \mathrm{C}$ for 12 hours without stirring. The obtained black plate of graphene hydrogel is washed with ethanol and water in a Soxhlet extractor for $24 \mathrm{~h}$ to remove residual impurities and then the wet hydrogels are freeze dried for 2 days to obtain 3D-G.

LiIHPN-LiI@3D-G electrode: After heating the finely ground powders of LiI and LiIHPN with a molar ratio of $1: 1$ onto the surface of $3 \mathrm{D}-\mathrm{G}$ electrode (weight of $300 \mu \mathrm{g}$, diameter $=$ $7 \mathrm{~mm}$, and $\mathrm{h}=1.2 \mathrm{~mm}$ ) at $130^{\circ} \mathrm{C}$ for one hour, these mixture powders (total weight of $8 \mathrm{mg}$ ) are melted into 3D-G electrode. LiIHPN-LiI@3D-G electrode can be easily formed after subsequently cooling to the room temperature.

\subsection{Measurements}

All-solid-state cell: All-solid-state batteries of Li/LiIHPN-LiI/LiIHPN-LiI@3D-G are constructed as following: Li plate (purity 99.999\%) with a thickness of $0.5 \mathrm{~mm}\left(2.0 \mathrm{~cm}^{2}\right)$ is used as an anode directly. Then, LiIHPN-LiI films $(\sim 100 \mu \mathrm{m})$ were coated onto the Li plate. LiIHPN-LiI@3D-G electrode (diameter=7 mm) is used as air electrode. Ni foam with a pore size of several hundred micrometers was used as the current collector. All-solid-state Li/LiIHPN-LiI/LiIHPN-LiI@3D-G battery can be assembled by simply pressing one Li/LiIHPN-LiI plate onto LiIHPN-LiI@3D-G electrode with the substrate of Ni foam in an Ar-filled dry glove box.

Single crystal test of LiIHPN: A suitable single-crystal particle with dimension of $0.250 \mathrm{x}$ $0.200 \times 0.130 \mathrm{~mm}^{3}$ is selected for X-ray diffraction. The crystal is sealed in a capillary to protect the sample from moisture. Diffraction data are collected on a Bruker AXS APEX 
CCD diffractometer equipped with a rotating anode using graphite-monochromated Mo K $\alpha$ radiation $(\lambda=0.71073 \AA$ ). Diffraction data are collected over the full sphere and corrected for absorption. The structures are solved by direct methods using SHELXS and refined against F2 on all data by full-matrix least squares with SHELXL-97. Details of the data collection and refinement are summarized in Table S1-4.

Conductivity measurement: The ionic conductivities are measured by electrochemical impedance spectroscopy (EIS). Conductivity measurement is carried out by using the sandwiching with two carbon electrodes and one columnar electrode of LiI: LiIHPN, which are obtained by cold pressing iodine lithium (purity 99.999\%) and LiIHPN with different molar ratio. Impedance data are obtained with an electrochemical working station CHI660C (Chenhua, China) in the frequency range $10 \mathrm{~Hz}-100 \mathrm{kHz}$ between $298 \mathrm{~K}$ and 355K. The conductivity of LiI: LiIHPN was calculated from Eq. (1) by the known area and the thickness as well as the examined resistance of C/ LiI: LiIHPN /C by a CHI660A electrochemical workstation.

$$
\sigma=d / R_{b} S
$$

where $R_{b}$ is the bulk resistance; $d$ is the thickness of the LiIHPN electrolyte, and $S$ is the area of the carbon electrode.

Transference numbers measurement: The electrolyte films of LiIHPN (diameter $=11.3 \mathrm{~mm}$, thickness $=0.12 \mathrm{~mm}$ ) are sandwiched between two carbon electrodes as a blocking type cells. LiIHPN electrolyte films are sandwiched between two lithium metal electrodes as the non-blocking type cells. The total number of ion transference is calculated based on Eq. (2):

$\mathrm{t}_{\text {ion }}=1-\mathrm{I}_{\mathrm{e}} / \mathrm{I}_{\mathrm{t}}$

Where $I_{t}$ and $I_{e}$ are the total and residual currents, respectively. The lithium ion transference numbers of LiIHPN electrolyte films were estimated by using an a.c. impedance combined with a d.c. polarization technique [15]. The a.c. impedance and the d.c. polarization curve of non-blocking-type cells (Li/LiIHPN/Li) are measured by a CHI660A electrochemical workstation. The step potential is $100 \mathrm{mV}$. The value of $t_{\mathrm{Li}+}$ is calculated from Eq. (3):

$\mathrm{t}_{\mathrm{Li}+}=\mathrm{Is}\left(\Delta \mathrm{V}-\mathrm{R}_{0} \mathrm{I}_{0}\right) / \mathrm{I}_{0}\left(\Delta \mathrm{V}-\mathrm{R}_{\mathrm{s}} \mathrm{I}_{\mathrm{s}}\right)$

Where $I_{0}$ and $I_{S}$ are the initial and final currents, respectively, and $R_{0}$ and $R_{S}$ are the cell resistances before and after the polarization, respectively. 
Charge-discharge measurements: Charge-discharge measurements are performed at 355K with a Land BT 1-40 battery test system. The current densities and capacities of electrodes are calculated based on the total mass of 3D-G materials.

Physical characterization: Scanning electron microscopy (SEM, Cambridge S-360) is employed to study the morphology of 3D-G and LiIHPN-LiI@3D-G electrode. Powder X-ray diffraction patterns were collected at beamline X7B of the National Synchrotron Light Source (NSLS) at Brookhaven National Laboratory. The wavelength used was $0.3196 \AA$. The morphology of 3D-G are investigated by battery backscattered electron imaging and energy-dispersive X-ray (EDX) spectra are captured using a FEI field-emission scanning electron microscope (Sirion XL) operated at an accelerating voltage of $20 \mathrm{kV}$. TEM and SAED measurements were carried out in a $200 \mathrm{kV}$ side entry JEOL 2010 TEM with an energy dispersive X-ray (EDX) analysers.

\subsection{Density function theory (DFT) calculations}

To understand microscopic ion transport mechanism in the $\operatorname{LiI}(\mathrm{HPN})_{\mathrm{n}}(\mathrm{n}=0,1,2)$ system, we carried out first-principles calculations adopting the Perdew-Burke-Ernzerhof (PBE) generalized gradient approximation (GGA) [16] and projector augmented waves (PAW)[17] pseudopotential as implemented in the Vienna ab initio simulation package (VASP) [18]. Intermolecular Forces of HPN (3-Hydroxypropionitrile) are not negligible, so we chose DFT-D2 method of Grimme in LiIHPN calculation [19]. We used a plane-wave cutoff energy of $520 \mathrm{eV}$ and $1 \times 3 \times 1$ Monkhorst-Pack k-point grid with Gaussian smearing of $0.20 \mathrm{eV}$ to relax the electronic energies and nuclear degrees of freedom. The calculations were performed in a monoclinic 8-f.u. $\mathrm{LiIC}_{3} \mathrm{H}_{5} \mathrm{NO}$ and all internal parameters were fully relaxed with the force convergence criterion of less than $0.02 \mathrm{eV} / \AA$, while the lattice parameters are optimized with a total energy convergence within $10^{-4} \mathrm{eV} /$ unit cell. The densities of states are obtained with a $\Gamma$-cantered $2 \times 5 \times 2$ meshes. The ion hopping barriers are obtained using the climbing image nudged elastic band (CINEB) method [20] with a total energy convergence within $10^{-4}$ $\mathrm{eV} /$ unit cell and force convergence within $0.05 \mathrm{eV} / \AA$. By comparison, FCC 4-f.u. LiI are calculated with a plane-wave cutoff energy of $230 \mathrm{eV}$ and $5 \times 5 \times 5$ Monkhorst-Pack k-point grid based on DFT method. A supercell consisting of $2 \times 2 \times 1$ primitive unit cells for LiI is selected in our CINEB calculations. The convergence criterions are the same as LiIHPN. The lattice parameters of a unit cell LiI, LiIHPN and LiI(HPN $)_{2}$ before and after optimize and the computational band gap are list in Table S1. The calculated average bond length for LiIHPN 
and $\operatorname{LiI}(\mathrm{HPN})_{2}$ and the bond length for related inorganic compounds [21-23] are listed in Table S3.

\section{Results and discussions}

The crystal structure of LiI: HPN=1:1 is shown in Figure 1(1). According to single-crystal structure analysis (Table 1), the molecular formula of the compound is $\mathrm{LiIC}_{3} \mathrm{H}_{5} \mathrm{NO}$ (LiIHPN) and the molecular weight is 204.92. It belongs to the C2/c space group with the monoclinic parameters $a=15.750(5) \AA, b=5.5760(18) \AA, c=16.139(7) \AA$, and $\beta=117.405(3)^{\circ}$. There are eight molecules in a unit cell. One lithium ion is coordinated with four atoms in the single-crystal structure of LiIHPN. For example, Li1 is coordinated with N1\#1 of the nitrile group, O1 of the hydroxyl group, two iodide atoms I1 and I1\#2. Two lithium ions are connected via two HPN molecules to form a closed 12-membered ring. Two neighboring rings are connected via iodide atom to form a 3-dimentional net-like structure. The bond length of Li1-N1\#1 is 1.982(2) $\AA$, Li1-O1 is 1.904(7) $\AA$, Li1-I1 is 2.742(7) $\AA$ and Li1-I1\#2 is 2.739(7) A. It is known that the bond lengths of Li-O and Li-N in inorganic compounds are in the range of 1.9-2.1 and 1.94-2.3 $\AA$, respectively. The above data indicates that strong chemical bonds between $\mathrm{Li}$ and $\mathrm{O}$ and $\mathrm{N}$ atoms exist in the LiIHPN. It should be noticed that each HPN molecule has two possible positions, which are shown as H1-O1-C1-C2-C3-N1 and H1-O1-C1'-C2'-C3-N1.

The structure of LiIHPN along a-, b- and c-axes are shown in Figure 1(2) respectively. The hydrogen bond, C1' and C2' are omitted for clarity. It is observed that each $\mathrm{Li}$ ion is almost in the central site of the tetrahedron surrounded by four atoms, i.e., one $\mathrm{N}$ atom in the nitrile group (-CN), one $\mathrm{O}$ atom in the hydroxyl group $(-\mathrm{OH})$ and two I atoms. Two sequent $\mathrm{Li}$ anions are connected via two organic molecules to form a closed twelve-membered ring. Different from iodide anion in $\operatorname{LiI}(\mathrm{HPN})_{2}$, iodide anion in LiIHPN is restrained by two Li ion and two hydrogen bonds of hydroxyl groups. As shown in the Table 2, the bond length of H1...I1 is 2.69(5) A. Details of other bond lengths, bond angles, and atomic coordinates for the single-crystal structure are listed in the Supporting Information Tables S1, S2.

In order to figure out the ion-conductor type of single crystal LiIHPN and the ion transport mechanism in LiIHPN crystal structure, we have calculated the ion hopping barrier for LiIHPN and LiI by using CINEB method, which can efficiently determine the pathway for 
structural changes and ion transport [24-26]. Through rotating the model of the crystal structure LiIHPN in Material Studio (MS), we found the space around each Li and I ion are very open along three directions. The distance between the two nearest neighboring Li or I ions in LiIHPN is 4.079 or $4.609 \AA$ and the ion radius of $\mathrm{Li}$ or $\mathrm{I}$ ion is 0.76 or $2.2 \AA$, respectively. We calculated the ion hopping barriers of LiIHPN by moving a Li or I ion to their nearest neighboring sites which had been removed ions beforehand to avoid blocking the way.

The energy barriers for LiIHPN are illustrated in Figure 2. The data from LiI are included for comparison. The energy barrier of $\mathrm{Li}$ ion in LiI $(0.39 \mathrm{eV})$ and LiIHPN $(0.57 \mathrm{eV})$ are lower than the case of I $(1.13 \mathrm{eV}, 0.81 \mathrm{eV})$, which indicate that the LiIHPN and LiI are Li ion conductors. Meanwhile, the difference of the energy barrier between $\mathrm{Li}$ and I ion in LiI (0.74 $\mathrm{eV})$ is larger than that in LiIHPN $(0.24 \mathrm{eV})$, but smaller than that in $\operatorname{LiI}(\mathrm{HPN})_{2}(-7.66 \mathrm{eV})$ [11]. These results indicate that the ion-conductor type of LiIHPN is Li ion, which is utterly different from $\mathrm{LiI}(\mathrm{HPN})_{2}$ as an I ion conductor. Apparently, the crystal structure change of synthesized LiIHPN after the mixture of $\mathrm{LiI}$ and $\mathrm{LiI}(\mathrm{HPN})_{2}$ annealing $130^{\circ} \mathrm{Cor} 48 \mathrm{~h}$ results in the different ion-conductor type from $\operatorname{LiI}(\mathrm{HPN})_{2}$.

XRD of LiIHPN powder is shown in Figure 3 and the simulation result is included for comparison. Apparently, all peaks from pure LiIHPN are in good agreement with the simulation of single crystal LiIHPN. It indicates that the LiIHPN can be synthesized without any impurity phase.

The dependence of ionic conductivity of LiIHPN on the temperature is shown in Figure 4. The values from $\mathrm{LiI}(\mathrm{HPN})_{2}$ and references are included for comparison. Both electrolytes of LiIHPN and LiI(HPN $)_{2}$ exhibit a typical Arrhenius behavior. Significantly, LiI(HPN $)_{2}$ is an I ion conductor while LiIHPN is a Li ion conductor. Their ionic conductivities were about $1.8 * 10^{-6}$ and $2.3^{*} 10^{-8} \mathrm{~S} / \mathrm{cm}$ at $25^{\circ} \mathrm{C}$, respectively. The experimental values of $\mathrm{LiI}(\mathrm{HPN})_{2}$ are well consistent with references. However, the data from LiIHPN synthesized in this work is utterly different from previous work[10], in which LiIHPN is synthesized by simply mixing LiI and $\operatorname{LiI}(\mathrm{HPN})_{2}$ with molar ratio of 1:1. Apparently the crystal structure of synthesized LiIHPN change after the mixture of LiI and $\operatorname{LiI}(\mathrm{HPN})_{2}$ annealing $130{ }^{\circ} \mathrm{C}$ for $48 \mathrm{~h}$.

The temperature dependence of the ionic conductivity of LiIHPN with the various LiI concentrations is shown in Figure 5. All of the composite electrolytes exhibit a well linear fit of an Arrhenius plots. Significantly, the enhancement of the ionic conductivity of LiIHPN with 
the addition of $\mathrm{LiI}$ is found. The ionic conductivity at $\mathrm{LiI} / \mathrm{LiIHPN}=1$ is $1.4^{*} 10^{-4} \mathrm{~S} / \mathrm{cm}$ in $328 \mathrm{~K}$ and is over two orders of magnitude higher than that of pure LiIHPN $\left(4.9 * 10^{-7} \mathrm{~S} / \mathrm{cm}\right)$. The highest conductivity of $1.8 * 10^{-3} \mathrm{~S} / \mathrm{cm}$ for the electrolyte from LiI/LiIHPN=1 can be achieved in 355K. The increasing concentration of Li ions with the introduction of LiI into LiIHPN should also be responsible for the enhancing ionic conductivity. In addition, it is known that the boundary region in composite material (As shown in the Figure S1, a physical mixture of LiIHPN with LiI is confirmed) is much larger than that in single system, which makes the transport of lithium easily. These reasons are beneficial to enhancing ionic conductivity with the addition of LiI into LiIHPN.

In order to study the electrochemical window of LiIHPN, a linear sweep polarization was performed at $355 \mathrm{~K}$. As shown in Figure 6, a wide electrochemical window of at least 5.5 V for the solid LiIHPN electrolyte is achieved. Such a wide window can be used for lithium-air batteries. The current responses of $\mathrm{Li} / \mathrm{LiIHPN} / \mathrm{Li}$ and $\mathrm{C} / \mathrm{LiIHPN} / \mathrm{C}$ as a function of time during voltage stepping from 0 to $0.1 \mathrm{~V}$ were examined to clarify the ion transference feature of LiIHPN as shown in Figure 7. When the potential is applied across C/LiIHPN/C, ionic and electronic conduction can be separated because Li ions are blocked by carbon contacts. The total $\left(\mathrm{I}_{\mathrm{t}}\right)$ and residual currents $\left(\mathrm{I}_{\mathrm{e}}\right)$ are 11.8 and $0.02 \mu \mathrm{A}$, respectively. The value of the total ionic transference number evaluated from Eq. (2) (in the Experimental section) is calculated to be 0.996, suggesting that the charge transport in the LiIHPN is ionic. The lithium ion transference number $\left(t_{\mathrm{Li}^{+}}\right)$has been evaluated by combining a.c. and d.c. techniques. The current evolution of $\mathrm{Li} / \mathrm{LiIHPN} / \mathrm{Li}$ with longer time is caused by the migration of $\mathrm{Li}$ ions in the LiIHPN. D.C. polarization curve of symmetric cells $\mathrm{Li} / \mathrm{LiI}(\mathrm{HPN}) / \mathrm{Li}$ indicates that the initial $\left(\mathrm{I}_{0}\right)$ and final currents $\left(\mathrm{I}_{\mathrm{S}}\right)$ are 3.49 and $3.33 \mu \mathrm{A}$, respectively. As shown in the insert of Figure 4, the cell resistances before $\left(\mathrm{R}_{0}\right)$ and after the polarization $\left(\mathrm{R}_{\mathrm{S}}\right)$ for $\mathrm{Li} / \mathrm{LiI}(\mathrm{HPN}) / \mathrm{Li}$ are 2314 and $2328 \Omega$, respectively. According to Eq. (3) in the Experimental section, $t_{\mathrm{Li}^{+}}$is evaluated to be 0.96 for the LiIHPN electrolyte. These results strongly support that LiIHPN is a Li ion conductor.

Three-dimensional graphene (3D-G) materials were used for air electrodes due to their unique mechanical characteristics, excellent electrical conductivity and large surface area. As shown in Figure 8, the graphene electrode obtained by freezedrying the graphene hydrogels exhibits similar 3D network structures composed of a large amount of interconnected macropores. Many ripples and wrinkles on the graphene electrode form the highly 
macroporous structure of the graphene, which enables small molecule electrolytes to be readily infiltrated, leading to 3D-G network-based conducting composites. In order to investigate the composition and morphology of LiIHPN-LiI@3D-G electrode, backscattered electron images of 3D-G electrode after the mixture powder of LiIHPN and LiI melted into 3D-G electrode were examined. The EDX results of LiIHPN-LiI@3D-G electrode are shown in Figure 9. It is clearly found that N, C, I, O elements are highly dispersed into the surface of LiIHPN-LiI@3D-G electrode. LiIHPN-LiI particles/clusters could closely anchor on the 3D-G and had intimate contact with 3D-G matrix. The LiIHPN-LiI@3D-G electrode offers a much larger contact area between 3D-G and solid-state electrolyte, which reduces the inner resistance of the electrode and facilitates electron and ion transportations to/from active sites during discharge/charge process, therefore may help in improving performance of lithium-air batteries.

Figure 10 shows the galvanostatic cycling profiles of the $\mathrm{Li} /$ LiIHPN-LiI/LiIHPN-LiI@3D-G cell in air ambient at the current densities of $67 \mathrm{~mA} \mathrm{~g}^{-1}$. In order to ensure the high value of Coulombic efficiency, the charge capacity is limited to $2740 \mathrm{mAh}$ $\mathrm{g}^{-1}$. The cell is discharged at a fixed voltage of $1.9 \mathrm{~V}$ to achieve the good cyclic performance. The open circuit voltage (OCV) of the cell was about 2.8 V. The first and second discharge capacities of the cell are about 1470 and $2100 \mathrm{mAh} \mathrm{g}^{-1}$, respectively. These measurements can carried out up to 10 cycles. This performance is close to that of previously reported all-solid-state Li-air battery (1000 $\mathrm{mAh} \mathrm{g}^{-1}$, cycle number of 10) [27], but need further to be improved. In order to further confirm the air electrode character, the charge-discharge performances of the Li/LiIHPN-LiI/LiIHPN-LiI@3D-G cell in Ar ambient for comparison is carried out (the red curves in the first cycle). In argon ambient, the discharge curve is almost drop line and the initial discharge capacity is less than $30 \mathrm{mAh} \mathrm{g}^{-1}$, indicating that there is no Faraday process during the discharge process. The discharge curve of the cell is significantly different from that in air ambient, indicating that LiIHPN-LiI@3D-G in air ambient is an air cathode. In addition, it can be found that the discharge capacity of Li/LiIHPN-LiI/LiIHPN-LiI@3D-G cell in Ar ambient is much lower than charge capacity, indicating the possibility of decomposition from the solid electrolyte. The decomposition of 
LiI from a physical mixture of LiIHPN-LiI electrolyte (Figure S1) was electrochemically driven by the graphene as an efficient catalyst.

In order to further grasp for the feature of air cathode, SEM and TEM images of 3D-G electrode after the discharging to $1.8 \mathrm{~V}$ are measured. As shown in Figure 11(a), many particles with the sizes about $150 \mathrm{~nm}$ are observed on the surface of the electrode at the discharged state. These particles are uniformly distributed in 3D-Gelectrode and closely anchored on graphene. Because of the existence of the LiIHPN-LiI thin film (less than $50 \mathrm{~nm}$ ) on the surface of graphene, the electrochemical reaction of $\mathrm{O}_{2}$ in air with lithium ions is limited to a local space between LiIHPN and graphene films, resulting in the coated nano-particles of the products with LiIHPN. The composition of discharged product was identified by TEM after the lithiated 3D-G electrodes are rinsed in an acetone to eliminate LiIHPN. Two-dimension lattices can be seen clearly in this image as shown in Figure 11(b). After measuring the d-space in two directions, they can be attributed to (200) of $\mathrm{Li}_{2} \mathrm{O}_{2}$. The SAED pattern in this phase shown in the insert of Figure 11(b) exhibits some rings made up of discrete spots, indicating the nanosized polycrystalline nature of the discharged product. All d-spacings derived from the SAED spectrum could be unambiguously indexed by the $\mathrm{Li}_{2} \mathrm{O}_{2}$ phase (JCPDS Card No. 73-1640, $\mathrm{Li}_{2} \mathrm{O}_{2}$ ).

It should be noted that the OCV of the Li/ LiIHPN-LiI/LiIHPN-LiI@3D-G cell in air ambient (2.8V) is lower than previous reported values of lithium-air batteries [7-9], which might be associated with the decomposed potential of LiI at $2.79 \mathrm{~V}$. On standing stage of the Li/ LiIHPN-LiI/LiIHPN-LiI@3D-G cell in air, the OCV of the Li/LiIHPN-LiI/LiIHPN-LiI@3D-G cell will be larger than $2.8 \mathrm{~V}$ if the active sites on air cathode are fully covered by $\mathrm{O}_{2}$ in air, this will result in the directly decomposition of LiI from LiIHPN-LiI@3D-G and the formation of $\mathrm{I}_{2}$ on the surface of air electrode. It is reasonable assumed that $\mathrm{I}_{2}$ instead of $\mathrm{O}_{2}$ is covered on surface of the air electrode at the primary state of the Li/LiIHPN-LiI/LiIHPN-LiI@3D-G cell. Thus, the electrochemical reaction mechanisms of the Li/LiIHPN-LiI/LiIHPN-LiI@3D-G cell at air electrode side are proposed as follows: 
During discharging:

$\mathrm{I}_{2}+2 \mathrm{e}^{-}+2 \mathrm{Li}^{+} \rightarrow 2 \mathrm{LiI}$

$\mathrm{O}_{2}+2 \mathrm{e}^{-}+2 \mathrm{Li}^{+} \rightarrow \mathrm{Li}_{2} \mathrm{O}_{2}$

During charging

$6 \mathrm{LiI} \rightarrow 2 \mathrm{I}_{3}^{-}+6 \mathrm{Li}^{+}+6 \mathrm{e}^{-}$

$2 \mathrm{I}_{3}^{-}+3 \mathrm{Li}_{2} \mathrm{O}_{2} \rightarrow 6 \mathrm{LiI}+3 \mathrm{O}_{2}$

$\mathrm{Li}$ ions will react with $\mathrm{I}_{2}$ from the decomposition of $\mathrm{LiI}$ on the air electrode to form $\mathrm{LiI}$ during the initial period of discharge process and can be expressed by equ. (4). After the $I_{2}$ at surface of air electrode is exhausted, the $\mathrm{O}_{2}$ in air will enrich on the air electrode instead of $\mathrm{I}_{2}$, the discharge process proceed with the electrochemical reaction of $\mathrm{O}_{2}$ as expressed by equ. (5). This could be used to explain for the feature of the discharge curve, in which a shorter sloping voltage plateau from 2.7 to $2.5 \mathrm{~V}$ (less than $250 \mathrm{mAh} \mathrm{g}^{-1}$, less than $10 \%$ of total discharge capacity ) and a sloping voltage plateau from 2.3 to $1.9 \mathrm{~V}$ are observed. They should correspond to discharge reactions of $\mathrm{I}_{2}$ and $\mathrm{O}_{2}$ on the air electrode with lithium, respectively. The discharge plateau from 2.3 to $1.9 \mathrm{~V}$ is lower than those of the previous reported Li-air batteries[5-6]. This may be due to the passivation after the reduction reaction process at 2.7 to $2.5 \mathrm{~V}$. The charge capacity of $2740 \mathrm{mAh} \mathrm{g}^{-1}$ is observed when the Li/LiIHPN-LiI/LiIHPN-LiI@3D-G cell in the Ar ambient. The initial charge peak centered at 2.74 V versus Li corresponds to the electrochemical decomposition of LiI electrochemically driven by the graphene as an efficient catalyst as described as equ. (6), which can be confirmed by Raman measurements (Figure S2). The charge potential vs. $\mathrm{Li}^{+} / \mathrm{Li}$ is less than that in a recently report[28]. The difference is mainly ascribed to the fact that the charge reaction of LiI occurs at high temperature of $355 \mathrm{~K}$ in the present work instead of at room temperature in Liu's work. The reverse charge process of Li/LiIHPN-LiI/LiIHPN-LiI@3D-G cell in air ambient should mainly involves the electrochemistry of LiI (equ. (6)) as Li/LiIHPN-LiI/LiIHPN-LiI@3D-G cell in Ar ambient and chemical reaction of $\mathrm{Li}_{2} \mathrm{O}_{2}$ with $\mathrm{I}_{3}{ }^{-}$ 
(supported by Raman data (Figure S2)), in which the oxidized product of $\mathrm{I}_{3}{ }^{-}$will spontaneously react with $\mathrm{Li}_{2} \mathrm{O}_{2}$ formed after the discharge process to re-generate LiI and release $\mathrm{O}_{2}$ at the air electrode side (equ. (7)). Obviously, Li/LiIHPN-LiI/LiIHPN-LiI@3D-G cell in air ambient is a typical lithium-air battery with LiIHPN as solid-state electrolyte and both LiI and graphene as catalysts.

\section{Conclusion}

The chemistry of small molecular compounds based on LiI and HPN is revealed, the manipulation of the ratio of LiI to HPN can design the different structural parameters and band energy of small molecular compounds. Interestingly, LiIHPN is a Li ion conductor, which is utterly different from previously reported $\mathrm{LiI}(\mathrm{HPN})_{2}$ as a I ion conductor. Furthermore, the all-solid-state lithium-air batteries could be achieved by using a perfect combination of LiIHPN electrolyte and LiIHPN-LiI@3D-G cathode. Our findings have demonstrated that a small molecular solid-state electrolyte based on organic and inorganic molecules can be employed for high performance lithium-air batteries for the first time.

\section{Supporting Information}

The supporting information is available free of charge via the Internet at http://pubs.acs.org. XRD patterns of a complex mixture of LiI and LiIHPN with different molar ratio of LiI/LiIHPN (Figure S1), Raman spectra of LiIHPN-LiI@3D-G air electrodes (Figure S2). The galvanostatic cycling profiles of the Li/ LiIHPN-LiI/LiIHPN-LiI@3D-G cell in air at the current density of 100 mA g${ }^{-1}$ (Figure S3) , SEM images of LiIHPN-LiI@3D-G aerogels (Figure S4), crystal data and structure parameters (Table S1-4).

\section{Acknowledgement}

This work was financially supported by the NSAF (Grant No.U1430104 and 51372228), Science \& Technology Commission of Shanghai Municipality (08DZ2270500) and Shanghai Pujiang Program (No. 14PJ1403900). All the computations were performed on the high performance computing platform of Shanghai University. The work at Brookhaven National 
Laboratory was supported by the U.S. Department of Energy, the Assistant Secretary for Energy Efficiency and Renewable Energy, Office of Vehicle Technologies under Contract No. DE-SC0012704.

\section{Corresponding Author}

sqshi@shu.edu.cn; zwfu@fudan.edu.cn 


\section{References}

[1] Sun, Y. Nano Energy 2013, 2, 801

[2] Shao, Y.; Ding, F.; Xiao, J.; Zhang, J.; Xu, W.; Park, S.; Zhang, J.G.; Wang, Y.; Liu, J. Adv. Funct. Mater. 2013, 23, 987

[3] Balaish, M.; Kraytsberg, A.; Ein-Eli, Y. Phys. Chem. Chem. Phys. 2014, 16, 2801

[4] Li, F.; Kitaura H.; Zhou, H. Energy Environ. Sci. 2013, 6, 2302

[5] Kitaura, H.; Zhou, H. Energy Environ. Sci. 2012, 5, 9077

[6] Kumar, J.; Kumar, B. J. Power Sources 2009, 194, 1113

[7] Abraham, K. M.; Jiang, Z. J. Electrochem. Soc. 1996, 43, 1

[8] Hassoun, J.; Croce, F.; Armand, M.; Scrosati, B. Angew. Chem. Int. Ed. 2011, 50, 2999

[9] Balaish, M.; Peled, E.; Golodnitsky, D.; Ein-Eli, Y. Angew. Chem., Int. Ed. 2015, 54, 436.

[10] Wang, H. X.; Li, H.; Xue, B. F.; Wang, Z. X.; Meng, Q. B.; Chen, L. Q.; J. Am. Chem. Soc. 2005, 127, 6394

[11] Shi, S. Q.; Xu, L. F.; Ouyang , C. Y.; Wang, Z. X.; Chen, L. Q.; Ionics 2006, 12, 343

[12] Wang, H. X.; Xue, B. F.; Hu, Y. S.; Wang, Z. X.; Meng, Q. B.; Huang, X. J.; Chen, L. Q. Electrochem. Solid-State Lett. 2004, 7, A302

[13] Wang, H. X.; Wang, Z. X.; Xue, B. F.; Meng, Q. B.; Huang, X. J.; Chen, L. Q. Chem. Commun. 2004, 19, 2186

[14] Zhang, L.; Chen, G. Y.; Hedhili, M. N.; Zhang, H.; Wang, P. Nanoscale 2012, 4, 7038

[15] Evans,C.; Vincent, A.; Bruce, P.G. Polymer 1987, 2, 2324

[16] Kresse, G.; Furthmuller, J. Phys. Rev. B 1996, 54, 11169

[17] Kresse, G.; Joubert, D. Phys. Rev. B 1999, 59, 1758

[18] Perdew, J. P.; Burke, K.; Ernzerhof, M. Phys. Rev. Lett. 1996, 77, 3865

[19] Grimme, S. J.; Comp. Chem. 2006, 27, 1787

[20] Henkelman, G.; Uberuaga, B. P.; Jonsson, H.; J. Chem. Phys. 2000,113, 9901

[21] (a) Zintl, E.; Harder, A.; Dauth, B. Trans J Br Ceram Soc. 1983, 83, 32;

[22] Schulzand, H.; Schwarz, K.; Acta Crystallogr. B 1978, 34, 999;

[23] Fischer, D.; Mueller A.; Jansen, M. Z.; Anorg. Allg. Chem. 2004, 630, 2697

[24] Wang, J. T.; Chen, C. F.; Kawazoe, Y.; Phys. Rev. B 2011, 84, 012102.

[25] Shen, G.; Ikuta, D.; Sinogeikin, S.; Zhang, Q.; Li, Y.; Chen, C. F.; Phys. Rev. Lett. 2012, 109, 205503 
[26] Zhang, Y.; Zhao, Y.S.; Chen, C. F.; Phys. Rev. B 2013, 87, 134303

[27] Liu, Y.; Li, B.; Kitaura, H.; Zhang, X.; Han, M.; He, P.; Zhou, H.; ACS Appl. Mater. Interfaces 2015, 7, 17307

[28] Liu, T.; Leskes, M.; Yu, W.; Moore, A.J.; Zhou, L.; Bayley, P.M.; Kim, G.; Grey, C.P., Science 2015, 355, 530 


\section{Table Captions:}

Table 1 Crystal Data and Structure Refinement for LiIHPN

Table 2 Bond Lengths and Angles of Hydrogen Bonds for LiIHPN ${ }^{b}$ 


\section{Figure Captions:}

Figure 1 (1) $\mathrm{Li}^{+}$cation coordination environment in the single-crystal structure of LiIHPN. Symmetry transformations used to generate equivalent atoms: \#1 -x+1/2,-y-3/2,-z+1; \#2 $-x+1 / 2, y+1 / 2,-z+1 / 2 ; \# 3-x+1 / 2, y-1 / 2,-z+1 / 2$. (2) $X$-ray structure plot for LiIHPN viewed along a, b and c axes. Two possible positions are shown as H1-O1-C1-C2-C3-N1 and H1-O1-C1'-C2'-C3-N1.

Figure 2 Calculated Li and I migration barriers for (a) LiIHPN and (b) LiI along selected paths

Figure 3 XRD patterns of the pure LiIHPN and its simulation are included for comparison

Figure 4 Arrhenius plots of LiIHPN and LiI(HPN) $)_{2}$ ionic conductivity

Figure 5 The temperature dependence of the ionic conductivity of on the LiI concentration in LiIHPN.

Figure 6 Linear sweep voltammogram at a scan rate of $1 \mathrm{mVs}^{-1}$ for the LiIHPN electrolyte Figure 7 Current responses of Li/LiIHPN/Li and C/LiIHPN/C when the potential was stepped from 0 to $0.1 \mathrm{~V}$ at $355 \mathrm{~K}$

Figure 8 SEM images of the 3D graphene with magnification of (a) 5000× and (b) 20000×.

Figure 9 (a)Backscattered electron images of LiIHPN-LiI@3D-G aerogels electrode and the corresponding energy-dispersive X-ray spectrometry mappings of (b) all elements; (c) C; (d)N; (e) O and (f) I elements.

Figure 10 The galvanostatic cycling profiles of the Li/ LiIHPN-LiI/LiIHPN-LiI@3D-G cell in air at the current densities of $67 \mathrm{~mA} \mathrm{~g}^{-1}$ (the charge capacity was limited to $2740 \mathrm{mAh} \mathrm{g}^{-1}$ )

Figure 11 (a) SEM images and (b) TEM images (its corresponding SAED pattern in the inset) of 3D-G electrode after the discharging to $1.8 \mathrm{~V}$. 
Table 1

\begin{tabular}{|l|l|}
\hline Empirical formula & $\mathrm{C}_{3} \mathrm{H}_{5} \mathrm{I} \mathrm{Li} \mathrm{N} \mathrm{O}$ \\
\hline Formula weight & 204.92 \\
\hline Crystal system & Monoclinic \\
\hline Space group & C2/c \\
\hline Crystal color & colorless, transparent \\
\hline Lattice params & \\
\hline$a(\AA)$ & $15.750(5)$ \\
\hline$b(\AA)$ & $5.5760(18)$ \\
\hline$c(\AA)$ & $16.139(7)$ \\
\hline$\beta($ deg$)$ & $\beta=117.405(3)^{\circ}$. \\
\hline Volume $\left(\AA^{3}\right)$ & $1258.2(8)$ \\
\hline$Z$ & 8 \\
\hline Density (calculated) & $2.163 \mathrm{~kg} / \mathrm{m}^{3}$ \\
\hline Absorption coefficient $\left(\mathrm{mm}^{-1}\right)$ & 4.973 \\
\hline F(000) & 752 \\
\hline Temperature $(\mathrm{K})$ & $293(2)$ \\
\hline Reflections collected & 3195 \\
\hline Refinement method & Full-matrix least-squares on $\mathrm{F}_{2}$ \\
\hline & \\
\hline
\end{tabular}


Table 2

\begin{tabular}{|l|l|l|l|l|}
\hline D-H...A & d(D-H) & d(H...A) & d(D...A) & $<$ (DHA) \\
\hline O1-H1...I1\#4 & $0.88(5)$ & $2.69(5)$ & $3.497(3)$ & $152(4)$ \\
\hline
\end{tabular}

${ }^{\mathrm{b}}$ Symmetry transformations used to generate equivalent atoms: $\# 1-\mathrm{x}+1 / 2,-\mathrm{y}-3 / 2,-\mathrm{z}+1$; $\# 2-x+1 / 2, y+1 / 2,-z+1 / 2 ; \# 3-x+1 / 2, y-1 / 2,-z+1 / 2 ; \# 4 x, y+1, z$ 
Figure 1
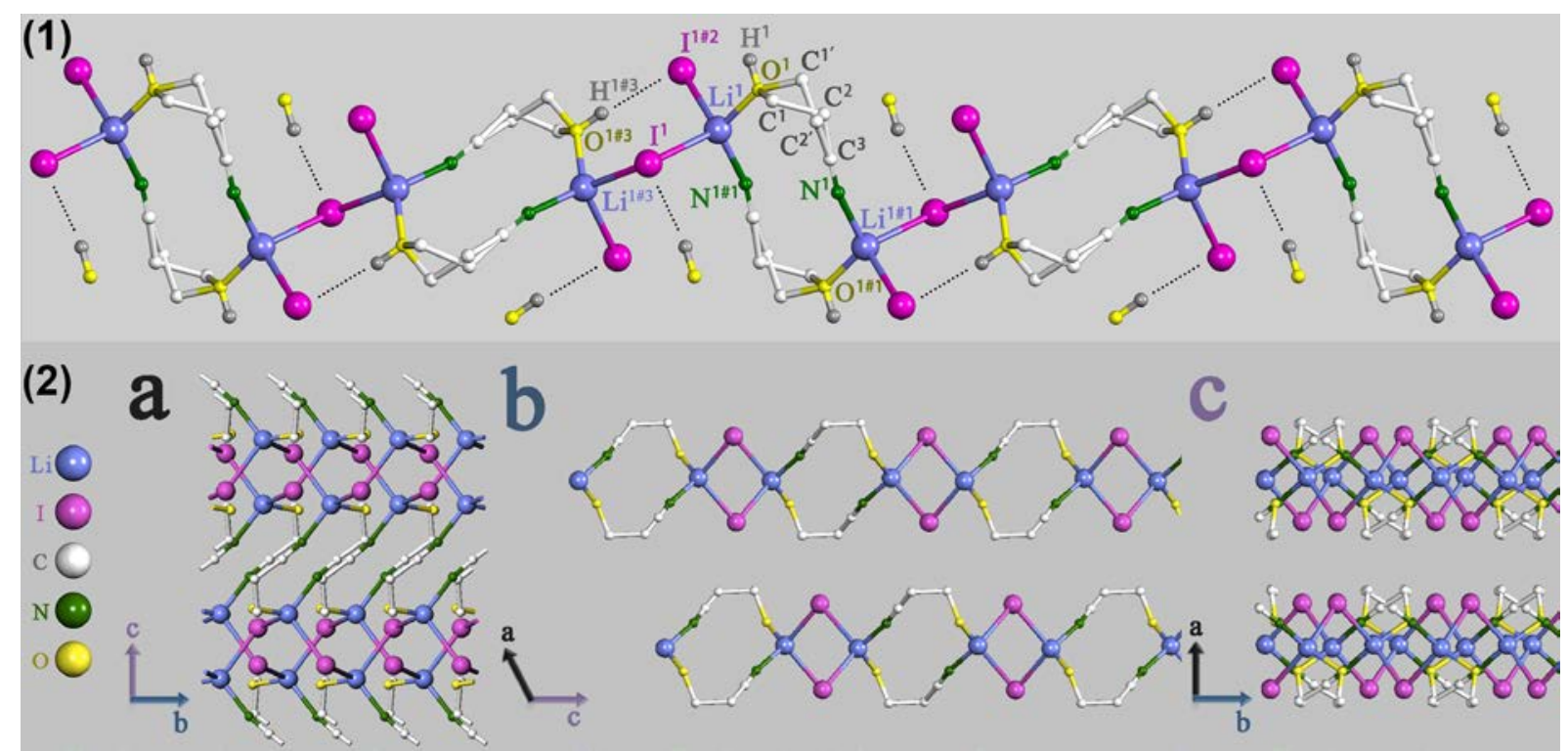
Figure 2

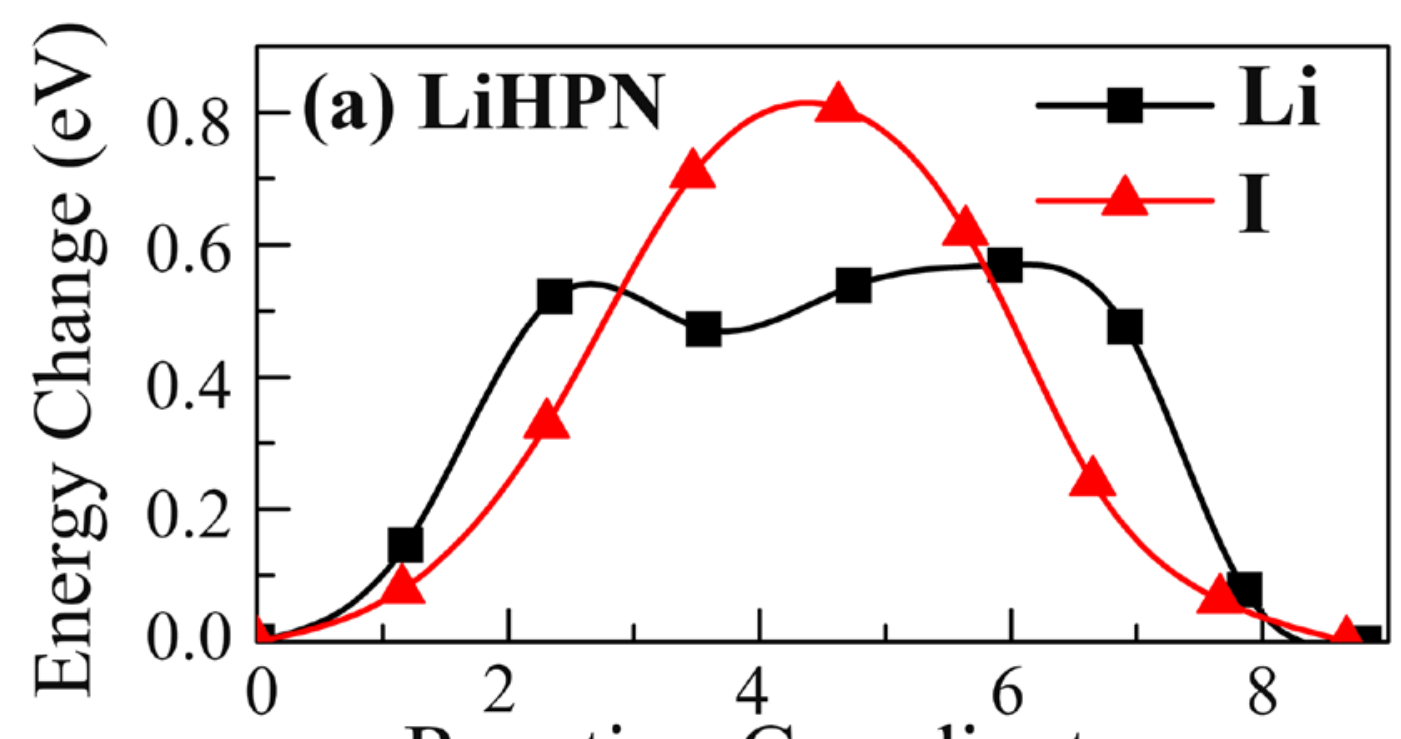

Reaction Coordinate

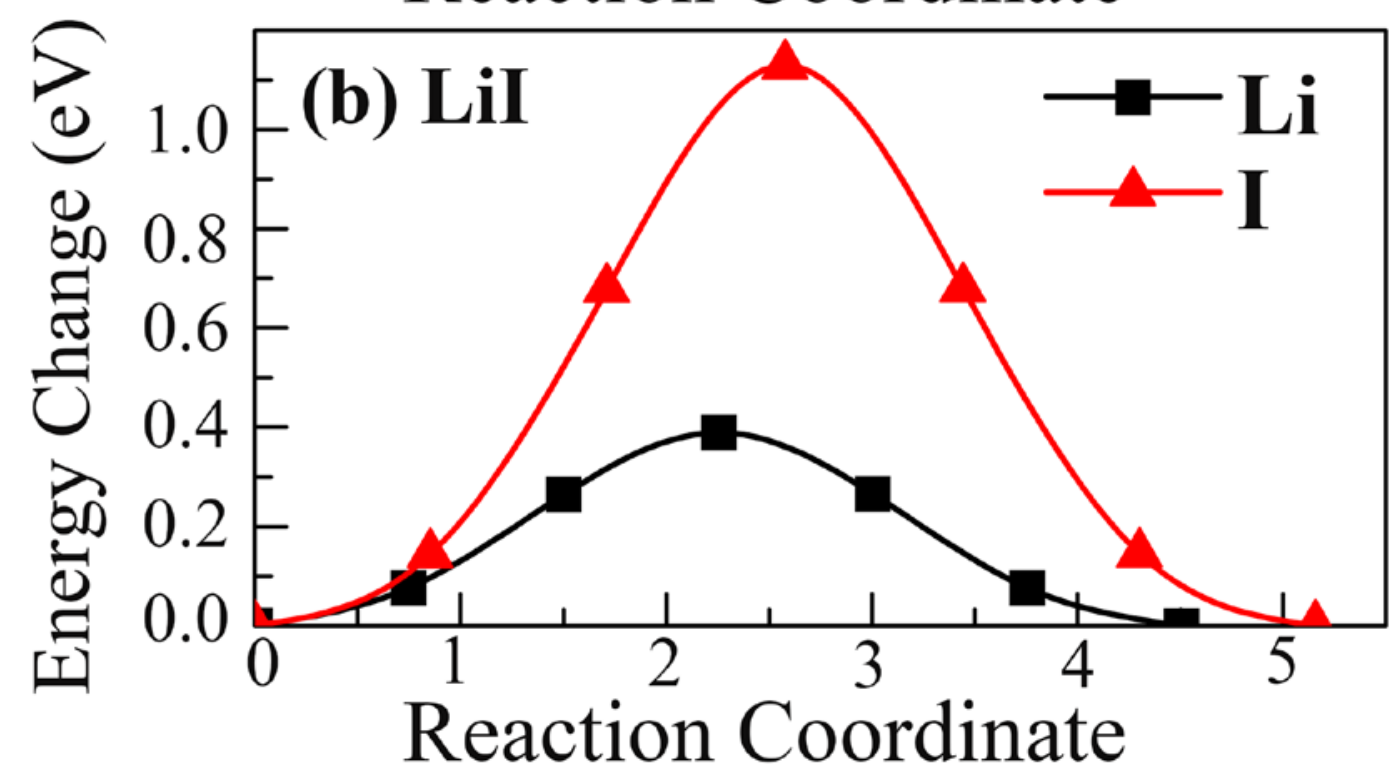


Figure 3

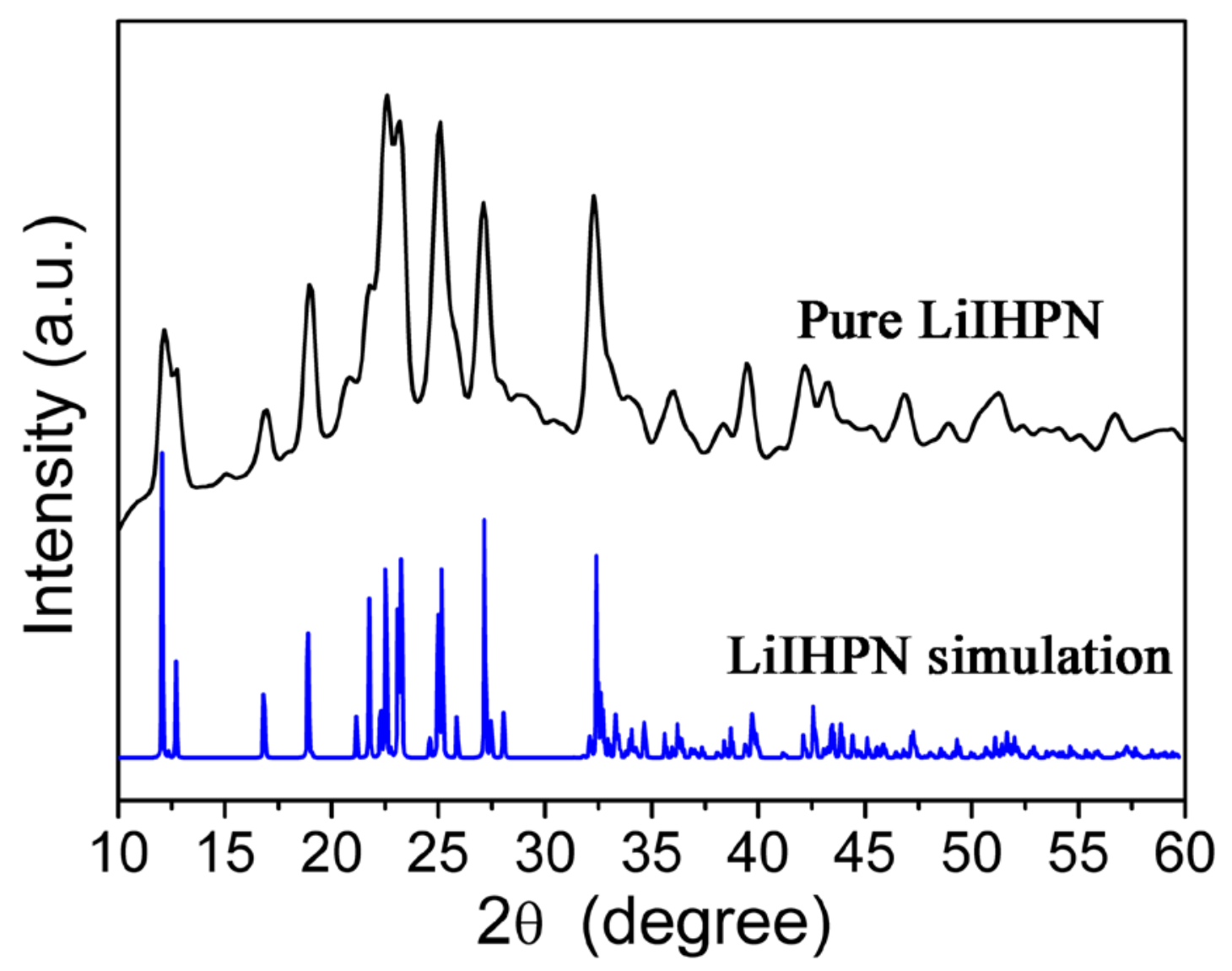


Figure 4

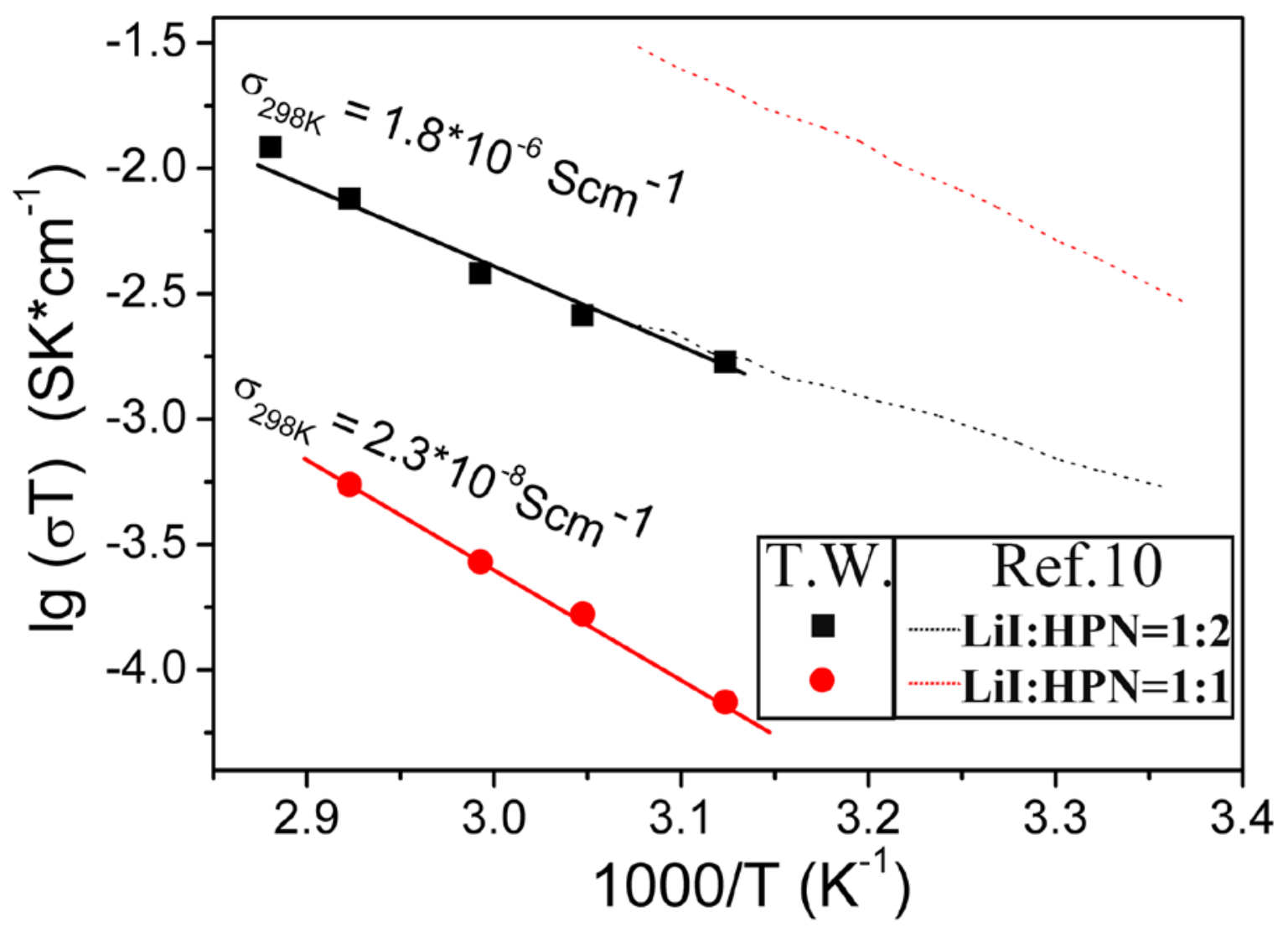


Figure 5

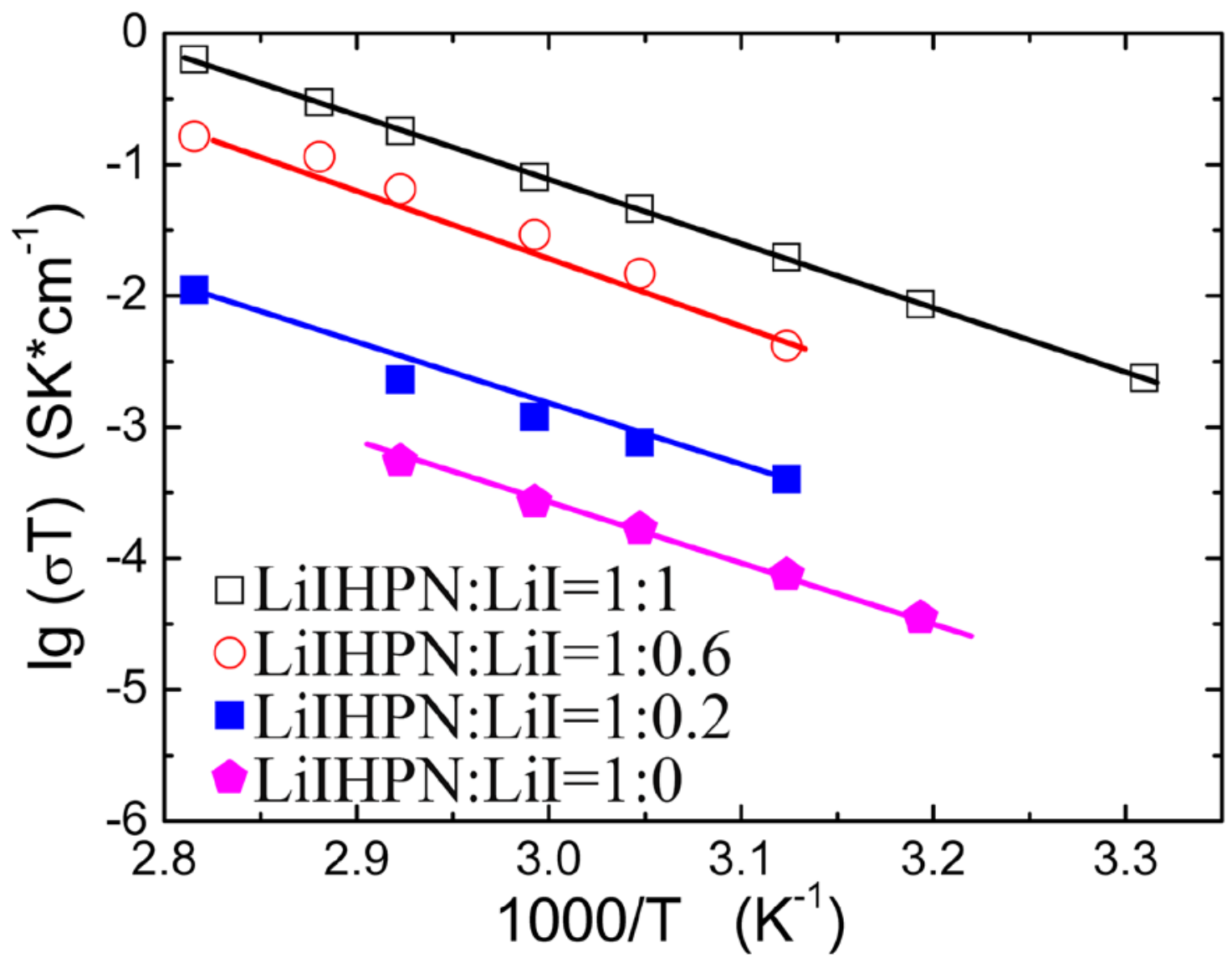


Figure 6

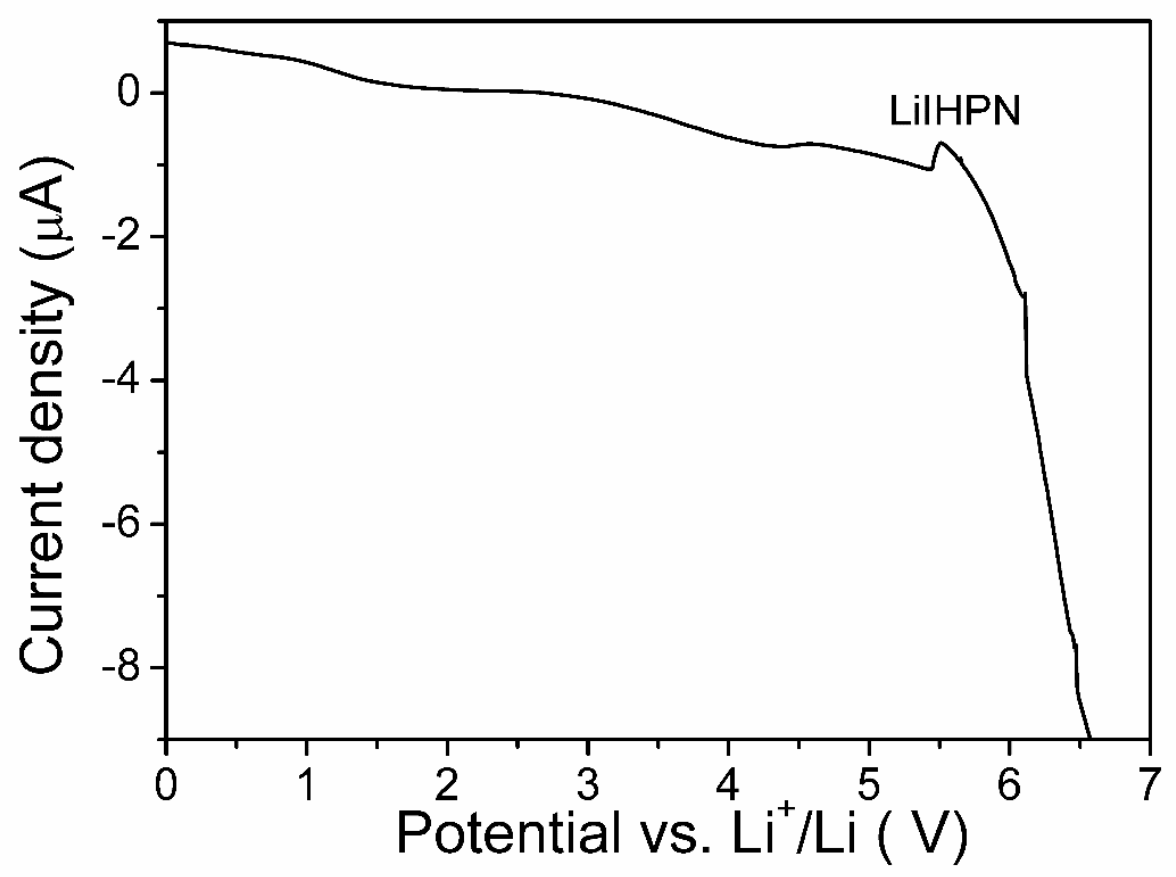


Figure 7

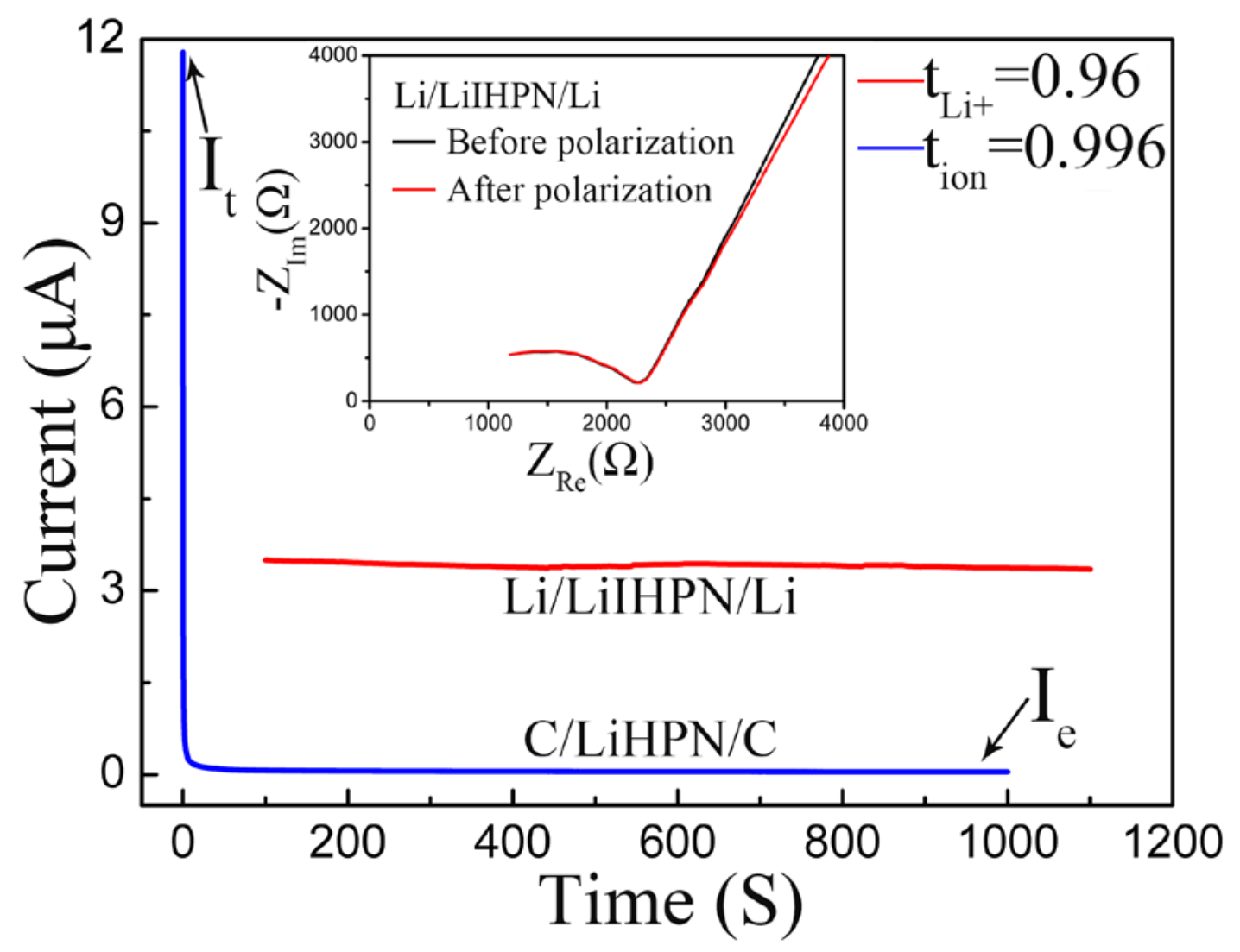


Figure 8

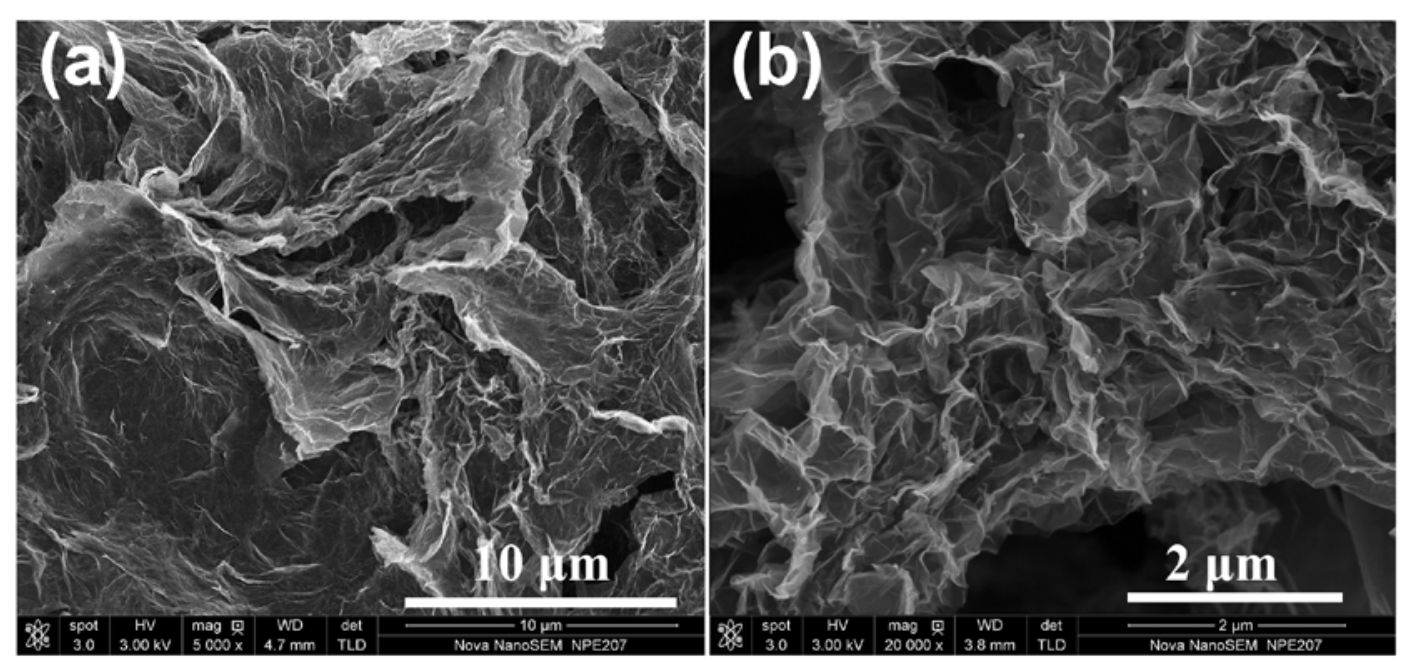


Figure 9

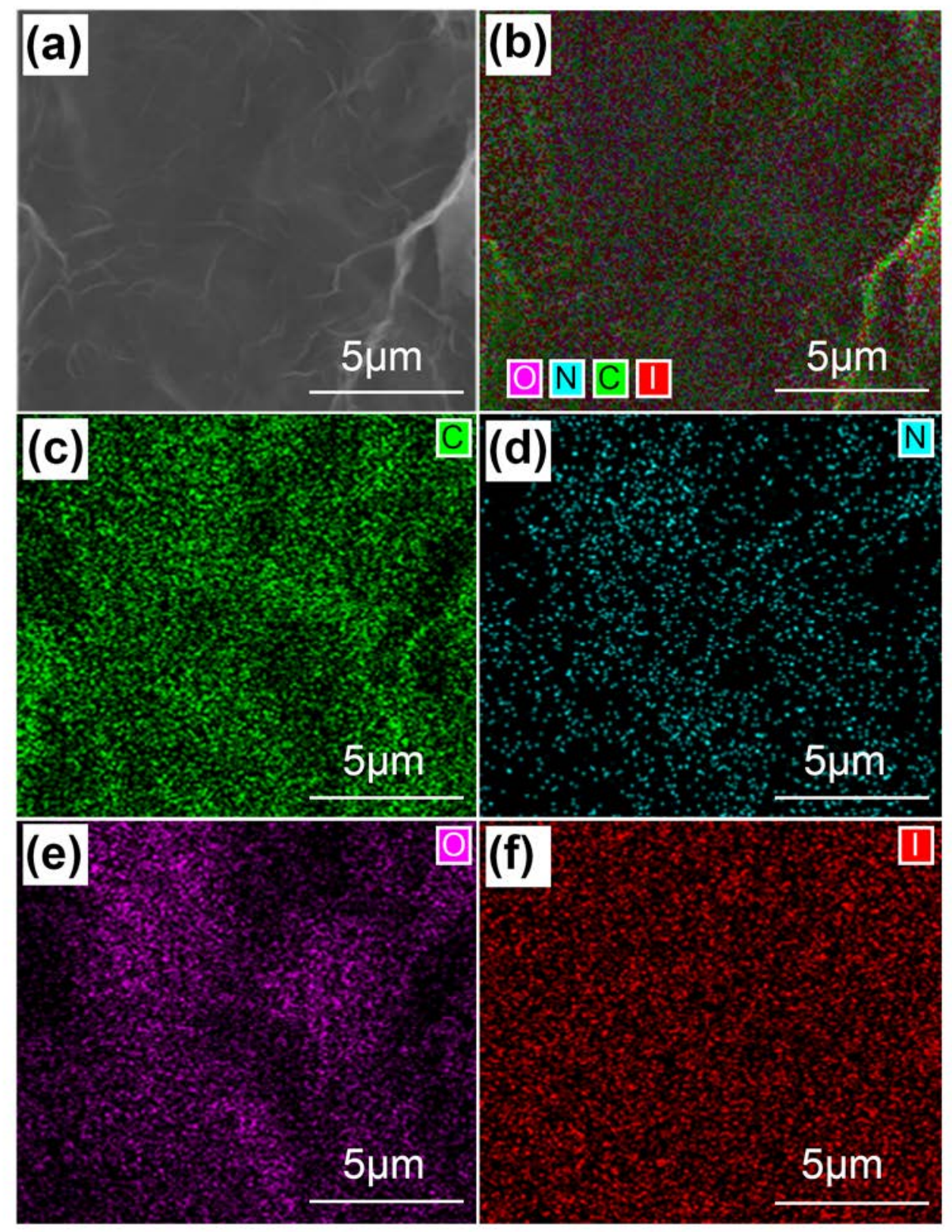


Figure 10

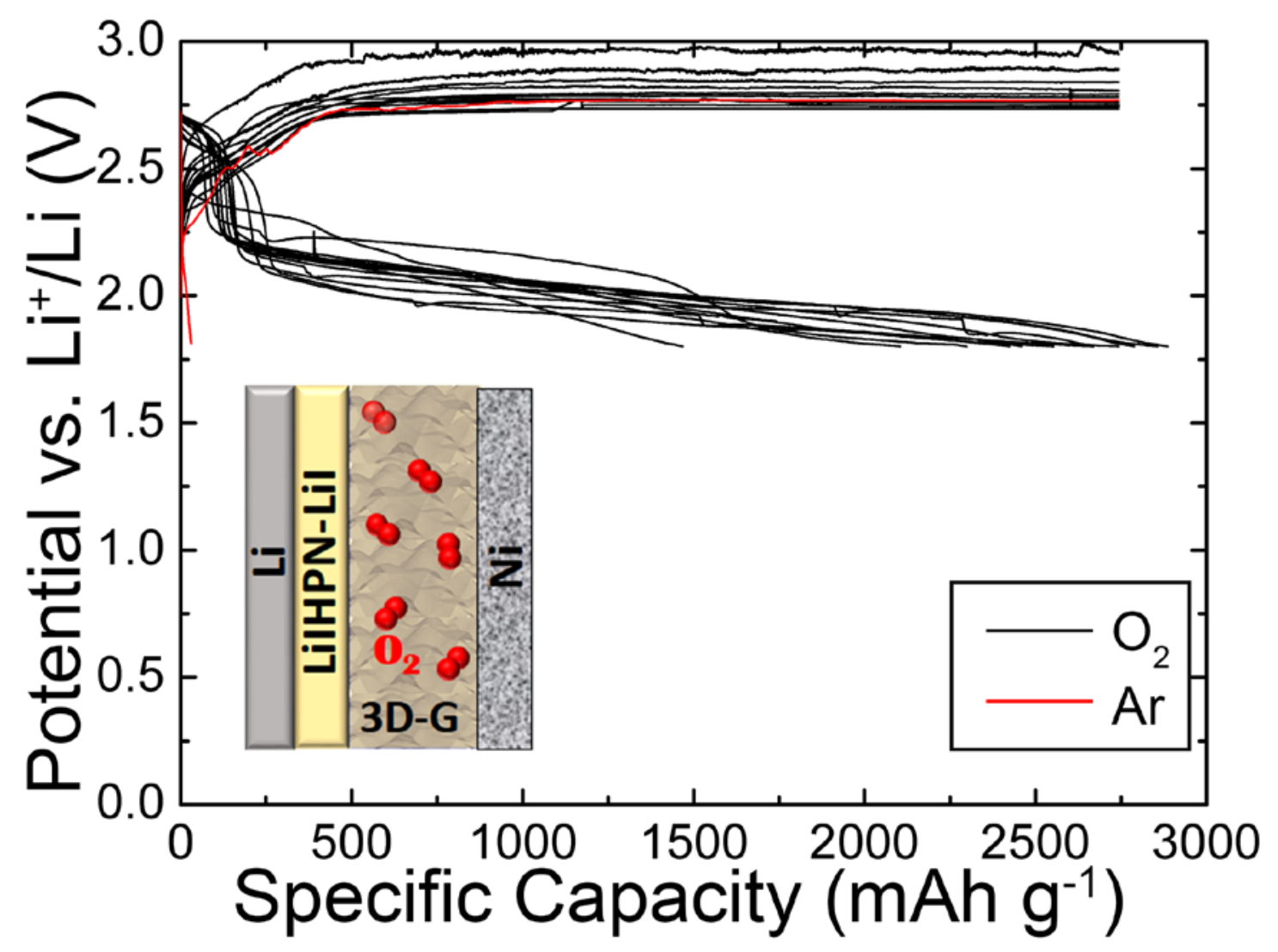


Figure 11

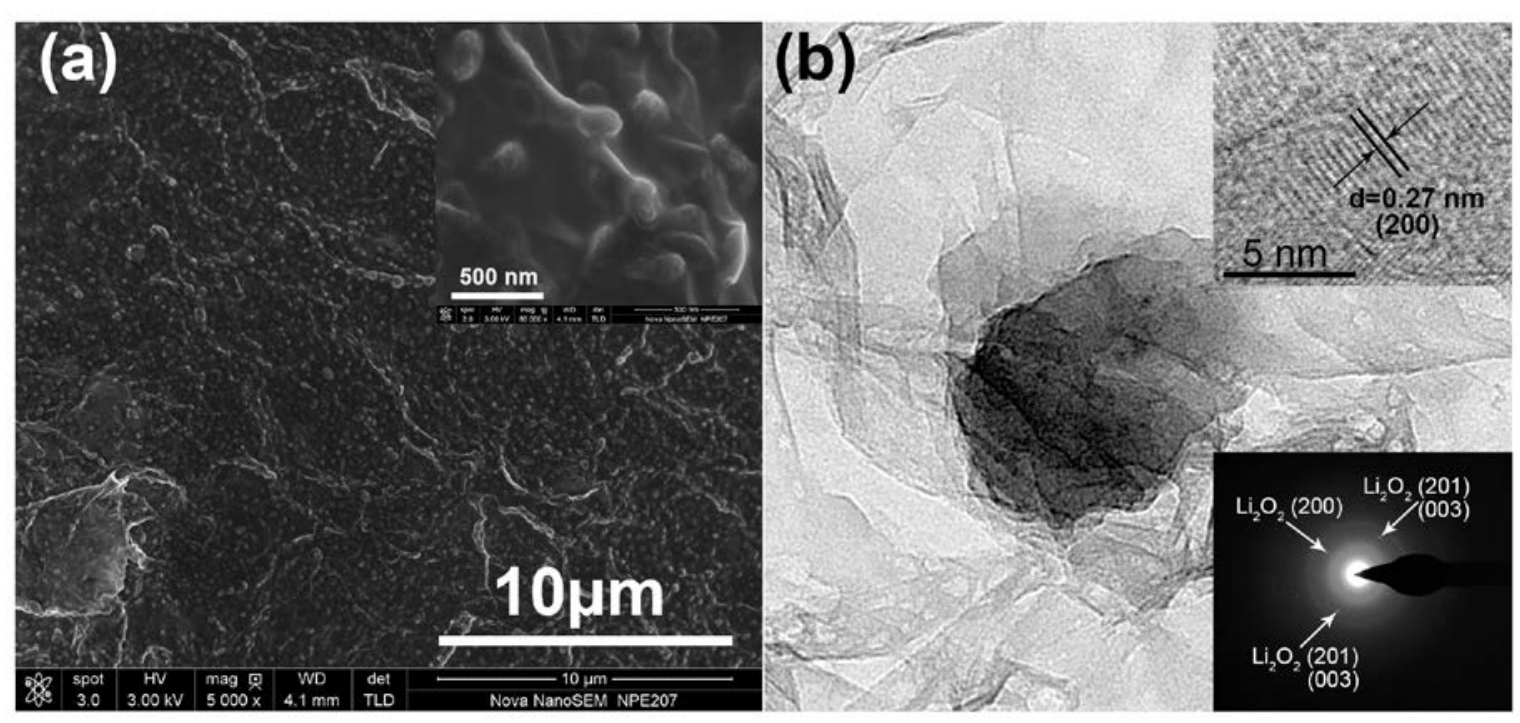


For Table of Contents Only

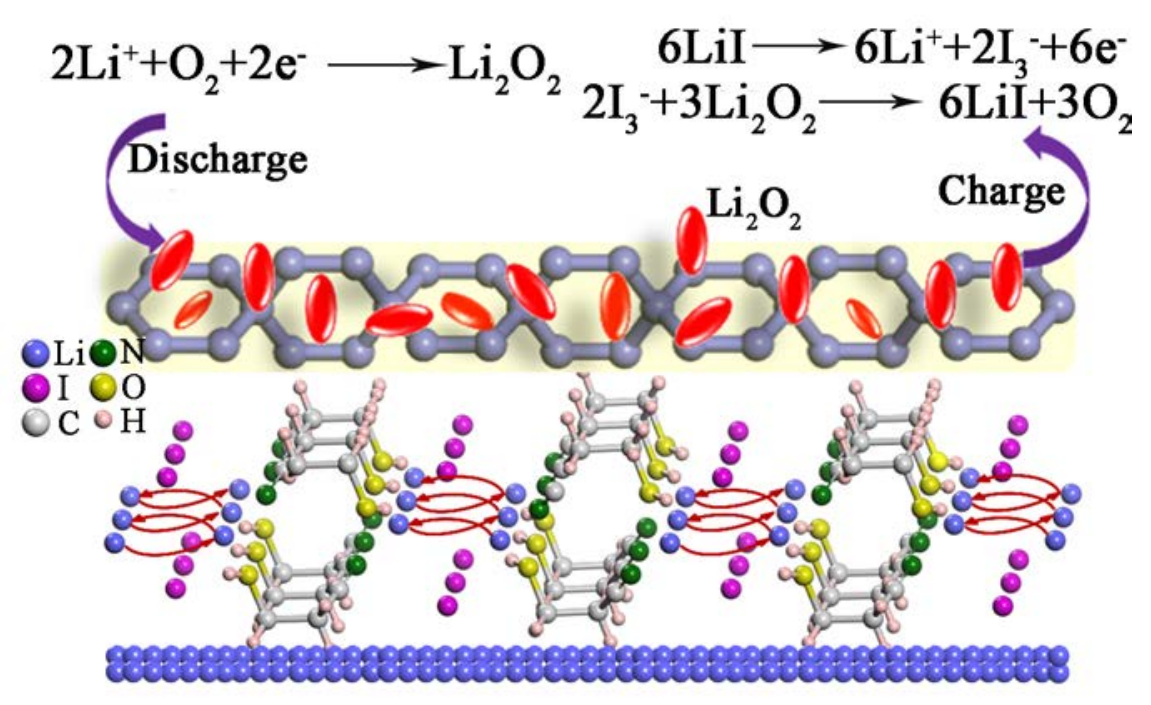

A new solid-state Li-ion conductor of LiIHPN has been successfully synthesized and was used for solid-state lithium-air batteries. Our results provide a new way for the design of solid-state electrolytes based on small organic and inorganic molecules towards high performance lithium-air batteries 